\title{
Prognostic Markers in Core-Binding Factor AML and Improved Survival with Multiple Consolidation Cycles of Intermediate/High-dose Cytarabine
}

Ashvind Prabahran', Mark Tacey², Shaun Fleming ${ }^{3}$, Andrew Wei $^{3}$, Courtney Tate $^{4}$, Paula Marlton $^{4}$, Joel Wight ${ }^{5}$, Andrew Grigg ${ }^{5}$, Annabel Tuckfield', Jeff Szer1, David Ritchie1, Lynette Chee',

'Department of Clinical Haematology and Bone Marrow Transplant Royal Melbourne Hospital

Victoria Australia

2Melbourne Epicentre Royal Melbourne Hospital Victoria Australia

3The Alfred Hospital Victoria Australia

${ }^{4}$ Princes Alexandra Hospital Queensland Australia

${ }^{5}$ The Austin Hospital Victorial Australia

\section{Corresponding Author}

Dr Ashvind Prabahran

Royal Melbourne Hospital

Ph: +61419468474

Email: aprabahr@gmail.com

Abstract word count: 198

Manuscript word count: 3558

Number of references: 29

Number of figures and tables: 3 Figures, 1 supplemental figure, 2 tables

Number of supplemental illustrations/tables:1 supplemental table

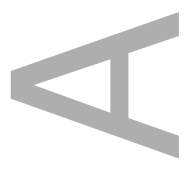

This is the author manuscript accepted for publication and has undergone full peer review but has not been through the copyediting, typesetting, pagination and proofreading process, which may lead to differences between this version and the Version of Record. Please cite this article as doi: $10.1111 /$ ejh.13089

This article is protected by copyright. All rights reserved 


\section{Abstract}

\section{Objectives}

Core-binding factor acute myeloid leukaemia (CBF AML) defined by $t(8 ; 21)(q 22 ; q 22)$ or $\operatorname{inv}(16)(p 13 q 22) / t(16 ; 16)(p 13 ; q 22)$ has a favourable prognosis, however $30-40 \%$ of patients still relapse after chemotherapy. We sought to evaluate risk factors for relapse in a de novo CBF AML cohort.

\section{Patients/Materials/Methods}

A retrospective review of patients from 4 Australian tertiary centres from 2001-2012, comprising 40 $\mathrm{t}(8 ; 21)$ and 30 inv(16) AMLs.

\section{Results}

Multivariate analysis identified age $(p=0.032)$ and WCC $>40(p=0.025)$ as significant predictors for inferior OS and relapse respectively. Relapse risk was higher in the inv(16) group vs the $t(8 ; 21)$ group ( $57 \%$ vs $18 \%$, HR $4.31,95 \% \mathrm{Cl}: 1.78-10.42$, p=0.001). Induction therapy had no bearing on OS or relapse free survival (RFS) however, consolidation treatment with $>3$ cycles of intermediate/high dose cytarabine improved OS ( $p=0.035)$ and relapse-free survival (RFS) $(p=0.063) .5$ patients demonstrated post-treatment stable q PCR positivity without relapse.

\section{Conclusions}

(1) $>3$ consolidation cycles of intermediate/ high-dose cytarabine improves patient outcomes

(2) Age and inv(16) CBF AML subtype are predictors of inferior OS and RFS respectively.

(3) Stable low-level MRD by qPCR does not predict relapse

(4) Similar OS in the inv(16) cohort compared to the $t(8 ; 21)$ cohort, despite a higher relapse rate, confirms salvageability of relapsed disease.

\section{Keywords: Acute Myeloid Leukaemia, Core binding factors, Prognosis}

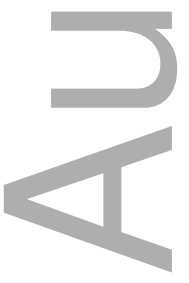

This article is protected by copyright. All rights reserved 


\section{Prognostic Markers in Core-Binding Factor AML and Improved Survival with Multiple Consolidation Cycles of Intermediate/High-dose Cytarabine}

\section{Introduction}

The core binding factor (CBF) positive acute myeloid leukaemias (AML) are defined by the cytogenetic abnormalities $t(8 ; 21)(q 22 ; q 22)$ or inv(16)(p13q22)/t(16;16)(p13;q22)(1). Aberrant transcripts resulting from these genetic rearrangements encode subunits of the core binding factor proteins. These abnormal subunits cause a block in myeloid differentiation leading to leukemogenesis(2). While commonly regarded as a "favourable" prognosis AML, $30-40 \%$ of patients still relapse after intensive chemotherapy(3). Risk factors predictive for relapse at diagnosis include older age, elevated white cell count (WCC), poor performance status, additional adverse-risk cytogenetics, concomitant receptor tyrosine kinase (RTK) mutations(4-6) and post-remission rising minimal residual disease (MRD) by molecular monitoring of the abnormal transcript(7-9).

The generally accepted standard induction regimen for CBF AML utilises anthracyclinebased (idarubicin $12 \mathrm{mg} / \mathrm{m}^{2} \mathrm{D} 1-3$ or daunorubicin $90 \mathrm{mg} / \mathrm{m}^{2} \mathrm{D} 1-3$ ) in combination with standard doses of cytarabine $\left(100-200 \mathrm{mg} / \mathrm{m}^{2} \mathrm{D} 1-7\right)(10-12)$. Subsequent consolidation treatment using high dose cytarabine $\left(3 \mathrm{~g} / \mathrm{m}^{2}\right.$ twice daily $\left.\mathrm{D} 1,3,5\right)$ has been demonstrated in the CALGB and JALSG trials to improve survival outcomes and reduce relapse rates in CBF $\operatorname{AML}(13,14)$. This benefit of multiple cycles of intensive therapy must be weighed against the potential for increased toxicity from high dose chemotherapy and poses a challenge in selecting the appropriate treatment in this group of patients(15).

In this study, we aim to evaluate the known risk factors, such as age, WCC and additional cytogenetics, as well as novel prognostic factors, such as molecular mutations and MRD, to provide additional prognostication strategies in assessing patients with CBF leukaemia. We also assessed the significance of treatment intensity, including number of consolidation cycles delivered, and the persistence of molecular positivity in complete remission (CR) post-treatment on clinical outcome.

\section{Methods and Patients}

\section{Patients}

A retrospective review was undertaken of adult CBF AML patients, identified through departmental leukaemia databases, treated at four major Australian centres from 2001-2012 with approval from institutional human research ethics committee. Eligibility consisted of age $>17$ years at diagnosis, de novo CBF AML defined as $t(8 ; 21)$ or $\operatorname{inv}(16) / t(16 ; 16)$ by 
conventional karyotyping and receipt of at least one cycle of intermediate dose cytarabine (defined as a minimum total dose of $4 \mathrm{~g} / \mathrm{m}^{2}$ in any cycle) during induction or consolidation.

All patients had at diagnosis a full blood examination, biochemistry and bone marrow biopsy with morphologic assessment, cytogenetics and molecular quantitative PCR (qPCR) testing for RUNX1-RUNX1T1 or CBFB-MYH11 fusion transcripts. Karyotype was identified by conventional cytogenetics and fluorescence in-situ hybridisation (FISH). Analysis of receptor tyrosine kinase (RTK) mutations, KIT and FLT3-ITD and TKD mutations was performed using techniques previously described(6).

\section{$\underline{\text { Treatment }}$}

Cytarabine was delivered in variable doses as part of different induction regimens as summarised in Table 1.

Following induction, patients received consolidation therapy with at least one cycle (range 16) of a cytarabine-containing regimen (Table 1).

\section{$\underline{\text { Response assessments }}$}

Bone marrow evaluation with karyotyping and/or FISH analysis was performed between D28-35 for assessment of remission status following induction chemotherapy. Morphologic response was assessed utilising the Cheson criteria(16). Complete remission (CR) status was defined by blast percentage of $<5 \%$. Karyotyping and/or $\mathrm{FISH}$ analysis were also undertaken.

Morphologic relapse was defined as $>5 \%$ of bone marrow blasts and molecular relapse was defined as increasing fusion transcript level of $>0.5 \mathrm{log}$. Allogeneic or autologous stem cell transplant depending on donor availability was performed for patients in molecular relapse or in those who achieved a subsequent remission following treatment for morphologic relapse.

Molecular MRD monitoring of RUNX1-RUNX1T1 or CBFB-MYH11 fusion transcripts by qPCR was performed on peripheral blood and/or bone marrow samples at diagnosis, postinduction, after each consolidation cycle and 3-monthly after completion of treatment for 2 years at one of two laboratories. We calculated log reductions of quantitative PCR values in comparison to diagnostic values, as one laboratory reported copy numbers while the other centralised Molecular Haematology laboratory reported \%CBFbetaMYHII/ABL or RUNX1RUNX1T1/ABL.

In the first laboratory, RUNX1-RUNX1T1 transcript detection was performed via qPCR using the Ipsogen RUNX1-RUNX1T1 Kit. The AML Kasumi-1 cell line was used as the 
positive control and $A B L$ as the housekeeping gene. Sensitivity of the assay is $10^{\wedge-4}$ copies of ABL. CBFB-MYH11 transcripts were assayed by 3 methods: 1) qPCR using the CBF $\beta$ MYH11 A Fusion Quant Kit which detects the CBF $\beta-M Y H 11$ A (Inv16 A) transcript; 2) a validated, in-house quantitative qPCR assay utilising Taqman chemistry to detect the CBF $\beta$ MYH11 D and E (Inv16 D and E) transcripts; and 3) a qualitative nested PCR + gel method to assess for rare translocations. The transcript standards contained in the respective kits are used as positive controls and $A B L$ is used as the housekeeping gene. Sensitivity of the assay $10^{\wedge-4}$ copies of ABL. QPCR was performed on an ABI Thermofisher SDS7500 instrument.

At the second laboratory, a validated in-house multiplexed PCR assay was used to detect the $R U N X 1-R U N X 1 T 1$ or CBFB-MYH11 A to $\mathrm{J}$ transcripts. This was followed by qPCR in which CBFB-MYH11 A, RUNX1-RUNX1T1 and ABL control were multiplexed to give a more accurate measure of sample RNA quality. Standard curves were prepared ranging from 10 to $10^{6}$ copies using cloned linearized DNA standards for RUNX1-RUNX1T1,CBFB-MYH11 A transcripts and $A B L$ supplied by Ipsogen (QIAGEN). Results were normalised to $10^{4}$ copies of $A B L$. Sensitivity was the same as the method in laboratory one. qPCR was performed on a Rotor Gene 5000 instrument.

Methods were validated and accredited to standards set by National Association of Testing Authorities, Australia (NATA) and the National Pathology Accreditation Advisory Council(17, 18)

\section{Statistical analysis}

Relapse free survival (RFS) and overall survival (OS) were calculated for the whole group and separately for the $t(8 ; 21)$ and inv(16) AML cohorts. Survival estimates were calculated using the Kaplan-Meier and log-rank test methods.

Categorical variables were analysed using a Chi-squared test, or a Fisher's exact test for variable counts $\leq 5$. Non-parametric (Mann-Whitney $U$ ) testing was used for the continuous variables that were non-normally distributed. Co-variates included in univariate Cox regression analysis were: age, WCC at diagnosis, gender, CBF AML subtype, additional cytogenetic abnormalities, RTK mutations (from 2006 onwards) and molecular MRD (defined as positive result above the threshold of detection as set by the individual laboratories) by qPCR at the different time-points (from 2003 onwards) and, with cases being censored after last contact confirming relapse or death. Multivariate Cox regression analysis was performed, using manual backwards step-wise regression techniques. 
Data were analysed using STATA v12.1 (StataCorp 2011, College Station, TX: StataCorp LP) and GraphPad PRISM (Version 7.0a for Mac, GraphPad Software, La Jolla California USA, www.graphpad.com), with a p-value of $<0.05$ considered to indicate statistical significance.

\section{Results}

Seventy patients were identified over the study period. Two patients from the $t(8 ; 21)$ cohort died during induction; the remaining 68 were available for follow up. The median follow-up period in surviving patients was 31.4 months (range 0.6-151.2).

\section{Patient Characteristics}

The patient characteristics are shown in Table 1 . There were 40 patients in the $t(8 ; 21)$ subgroup and 30 patients in the inv(16) subgroup, with no significant differences in patients aged over 50, median age or of male gender. The proportion of patients with $W C C \geq 40 \times 10^{9} / L$ at diagnosis was higher in the inv(16) group compared to the $t(8 ; 21)$ group ( $40 \%$ vs $8 \%, p=0.001)$ as was the proportion of patients without additional cytogenetic abnormalities $(72 \%$ vs $59 \%, p=0.029)$. The induction regimens and numbers of high, intermediate or standard dose cytarabine cycles administered during consolidation are shown in Table 1. There were no differences in the type and intensity of induction or consolidation treatments received between the inv(16) and $t(8 ; 21)$ groups.

\section{Treatment received}

Standard dose $\left(700 \mathrm{mg} / \mathrm{m}^{2}\right)$ in comparison to intermediate/ high-dose cytarabine $\left(4-24 \mathrm{~g} / \mathrm{m}^{2}\right)$ for induction had no differential impact on OS or RFS.

The median number of consolidation cycles received was 2 (range 0-6). There was no significant difference in median age between groups receiving $\leq 2$ or $\geq 3$ consolidation cycles. ( $\leq 2: n=37,47$ years, $\geq 3$ : $n=30,35.5$ years, $p=0.236$ ).

Patients who received $\geq 3$ consolidation cycles of IDAC/HIDAC had significantly improved OS (HR 0.20, 95\% Cl 0.04-0.89, $\mathrm{p}=0.035$ ) in comparison to $\leq 2$ cycles (Fig 1a). An improved RFS was also observed in the former group ( $p=0.063$ ) (Fig 1b), largely in the inv(16) cohort, with those receiving 3 consolidation cycles having a median RFS of 28 months in comparison to $<3$ cycles of 8 months (HR 0.20, 95\% Cl: $0.06-0.69, \mathrm{p}=0.011$ ) (Fig 1c). There was no difference in RFS for the $\mathrm{t}(8 ; 21)$ cohort (HR 1.71, 95\% Cl: $0.36-8.00, p=0.497$ ) (Fig 1c). Overall, in the relapsed cohort, median RFS was not statistically significant for the $<3$ in comparison to $\geq 3$ consolidation cycles of IDAC/HIDAC groups ( 8.1 months vs 9.8 months). 
Further stratification of cytarabine doses and number of cycles $(<3$ or $\geq 3)$ received in consolidation (standard vs intermediate $4-6 \mathrm{~g} / \mathrm{m}^{2}$ vs high dose $18-24 \mathrm{~g} / \mathrm{m}^{2}$ ) demonstrated no impact on relapse nor survival outcomes, likely hampered by low numbers in each group.

The cumulative doses of anthracyclines (range $0-108 \mathrm{mg} / \mathrm{m}^{2}$ of idarubicin) received was also analysed in this cohort. There was no significant effect on relapse nor OS for patients receiving doses of $\leq 36 \mathrm{mg} / \mathrm{m}^{2}(\mathrm{n}=41,59.6 \%)$ in comparison to $>36 \mathrm{mg} / \mathrm{m}^{2} \quad(n=29,41.4 \%)$.

\section{$\underline{\text { Response and Survival Outcomes }}$}

Sixty eight of the 70 patients achieved a morphologic CR (97\%). OS for the cohort was $71 \%$ and RFS was $59 \%$ (Figures $2 a$ and $2 b$ ) at 5 years. There was no significant difference in OS between the $\operatorname{inv}(16)$ and $t(8: 21)$ groups $(p=0.281)$ (Fig $2 c)$. In contrast, relapse risk was higher in the inv(16) group when compared to the $t(8 ; 21)$ group ( $57 \%$ vs $18 \%$, HR $4.31,95 \%$ Cl: 1.78-10.42, $p=0.001$ ) (Tables $2 a$ and $2 b$ ). RFS was significantly worse for inv(16) compared to $t(8: 21)(p<0.001)$ being $39 \%$ and $75 \%$, respectively (Fig $2 d)$.

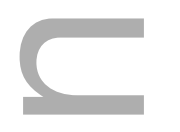

There were 24 relapses (17 in the inv(16) group and 7 in the $t(8: 21)$ group) occurring at a median of 9 months (range 4 to 56.2 months) after achieving remission. Twenty-two had a morphologic relapse and 2 had a molecular relapse. Median OS from time of diagnosis for the relapsed cohort was 29.9 months (range 8.3-148.8 months) (Supplemental Figure 1a). Sixteen of 24 patients received re-induction chemotherapy (without use of Gemtuzumab), 1 patient received Azacitidine treatment, 3 proceeded directly to allogeneic stem cell transplant (SCT) with myeloablative conditioning and 1 was managed with supportive care. One patient received intrathecal cytarabine and methotrexate followed by high dose intravenous methotrexate for CNS relapse while the salvage regimen in 2 relapsed patients is unknown.

Fifteen patients in total proceeded to a SCT; 13 had an allogeneic SCT (8 inv(16) and 5 $t(8 ; 21))$ and 2 inv(16) patients had an autologous SCT. There was one allogeneic SCT done in CR1 for a $t(8 ; 21)$ patient who developed complications of renal and respiratory failure following induction chemotherapy, and further consolidation cycles could not be delivered. At 3 years, OS was $54 \%$ for allogeneic SCT patients, $25 \%$ for those who did not proceed to transplant and both autologous SCT patients are still alive (Supplemental Fig 1b). In the allograft group, there were 6 deaths; 3 due to relapsed disease post-allograft, 2 from graftversus-host disease (GVHD) and 1 from non-GVHD complications. Median OS was not reached in the allograft and autograft patients, and 14.1 months in the non-transplant group. 
Overall there were 16 deaths (9 in the inv(16) group and 7 in the $t(8 ; 21)$ group). 9 were from relapsed AML, 6 from treatment-related complications including the 2 cases of GVHD and 1 unrelated to AML.

\section{$\underline{\text { OS }}$}

Univariate and multivariate analysis identified age as a significant predictor of inferior OS (HR 1.03, 95\% Cl: 1.00-1.06, $\mathrm{p}=0.032$ ), with further analysis of different age thresholds revealing age greater than 50 to be a significant predictor of OS $(\mathrm{HR} 2.95,95 \% \mathrm{Cl}: 1.07-$ 8.14, $\mathrm{p}=0.036$ ) (Table $2 \mathrm{a}$ and Fig 3a). WCC at diagnosis was not predictive of OS outcomes.

Additional cytogenetic abnormalities are listed in Tables 1 and 2a. Statistical analysis was performed according to three different groups: No additional abnormalities, additional abnormalities $(<3)$ or complex 3 ( abnormalities). There were no differences in OS demonstrated for any cytogenetic subgroup. With regards to molecular mutational analysis, KIT mutation ( $\mathrm{n}=34$, Positive $=14$, Negative $=20, \mathrm{p}=0.158)$ or FLT3 mutation $(\mathrm{n}=27$, Positive $=2$, Negative $=25, p=0.152$ ) were not predictive of inferior OS.

\section{$\underline{\text { RFS }}$}

On univariate analysis, the WCC at diagnosis was a significant predictor of RFS (Table 2b) but not OS. The median WCC for the entire cohort was $14 \times 10^{9} / \mathrm{L}$ (range 2-215) with inv $(16)$ patients having a higher median WCC of $33 \times 10^{9} / \mathrm{L}$ (inter-quartile range (IQR): $11 \times 10^{9} / \mathrm{L}$ to $\left.67.5 \times 10^{9} / \mathrm{L}\right)$ in comparison to the $\mathrm{t}(8 ; 21)$ cohort with $10.5 \times 10^{9} / \mathrm{L}\left(\mathrm{IQR}: 5 \times 10^{9} / \mathrm{L}\right.$ to $\left.19 \times 10^{9} / \mathrm{L}\right)$

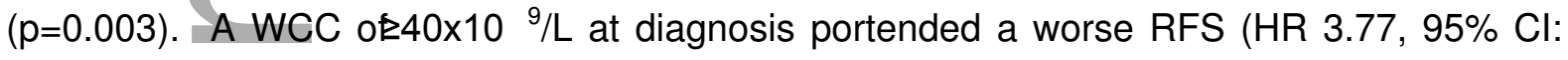
1.64-8.69, $p=0.002$, Fig 3b).

For molecular mutational analysis, both the KIT and FLT3 mutations were not predictive of RFS outcomes. However, the data for these variables were incomplete, with significantly fewer results available from patients who relapsed. Hence, KIT and FLT3 mutations could not be included in the multivariate analysis.

Upon multivariate analysis, the CBF AML subtype was the only significant predictor of relapse (HR 4.31, 95\%Cl:1.78-10.42). WCC was not independently associated with RFS after adjustment for the CBF AML subtype $(p=0.108)$, but the $\mathrm{HR}$ of $2.13(95 \% \mathrm{Cl}: 0.85-5.33)$ and the reduction of the HR for CBF AML subtype upon inclusion of WCC into the multivariate model (HR 3.34, 95\% $\mathrm{Cl}$ : 1.26-8.85) indicates that the limited sample size may prevent WCC from reaching independent statistical significance along with the stronger effect of CBL AML subtype. There was a significant interaction between CBF AML subtype 
and median WCC for both relapse (HR 6.54, 95\%Cl: 1.02-41.82, $\mathrm{p}=0.047)$ and OS (HR 16.19, $95 \% \mathrm{Cl}: 2.13-123.37, \mathrm{p}=0.007)$, although this interaction failed to reach statistical significance upon multivariate analysis, possibly due to the limited sample size.

\section{MRD and impact on clinical outcome}

Thirty-seven of 68 patients had qPCR data available post-induction (MRD1), 24 of 66 postconsolidation 1 (MRD2), 28 of 54 post-consolidation 2 (MRD3), 23 of 30 post-consolidation 3 (MRD4) and 12 of 19 post-consolidation 4 (MRD5). The number of patients who achieved $\geq 3$ or $<3$ log reduction and number of relapses/deaths at each MRD timepoint are detailed in Supplemental Table 1. MRD, as measured by log reduction, was not predictive of OS and RFS at any timepoint.

\section{MRD monitoring post-completion of treatment}

Fusion transcript ratio in the BM showed a faster decline in the inv(16) group in comparison to $t(8 ; 21)$ group (Figs $4 a$ and $4 b)$. Mean \pm SEM values for each time-point:

inv(16): Diagnosis $-64.9 \pm 15.4, M R D 1-0.009 \pm 0.008, M R D 2-0.0 \pm 0.0$, MRD3 $-0.05 \pm$ 0.05, MRD4 $-0.02 \pm 0.02$, MRD5 $-0.0 \pm 0.0$

$\mathrm{t}(8 ; 21)$ : Diagnosis $-294.0 \pm 52.9, \mathrm{MRD} 1-9.2 \pm 4.7, \mathrm{MRD} 2-0.9 \pm 0.6, \mathrm{MRD} 3-0.4 \pm 0.3$, MRD4 $-0.2 \pm 0.1$, MRD5 $-0.2 \pm 0.2$

Of the 43 with durable CR, 28 maintained PB or BM qPCR values of $0-0.1 \%$ or $<10$ copy numbers throughout follow-up for 2 years post-completion of consolidation treatment. Six had $\mathrm{qPCR}$ values $>0.1 \%$ or $>50$ copy numbers; 5 were $t(8 ; 21)$ who subsequently achieved PCR negativity at a range of 9-24 months post-completion of consolidation. One inv(16) patient subsequently relapsed, while 9 patients had no further monitoring conducted.

Median BM qPCR values increased from $0 \%$ (range $0-0.59$ ) to $11 \%$ (range $3.4-18.1$ ) at relapse for inv(16) at a median duration of 4.3 months (range $1-8$ ) and $0.05 \%$ (range $0-0.47$ ) to $178 \%$ (range $34-1139$ ) for $t(8 ; 21)$ at 6 months (range $5-35)$, respectively.

\section{Discussion}

In this study, we demonstrate: (1) the beneficial effect of multiple cycles $(\geq 3)$ of intermediate/ high-dose cytarabine during consolidation on OS and RFS, (2) the importance of age and inv(16) CBF AML subtype in predicting inferior OS and RFS respectively, (3) stable low-level MRD did not predict relapse and (4) OS was similar in the inv(16) cohort in comparison to 
the $t(8 ; 21)$ cohort despite a higher relapse rate in the former group, confirming salvageability of relapsed disease with stem cell transplantation.

Cytarabine is the most important agent in the treatment of the disease but the dose used during induction has less impact on clinical outcome provided sufficient doses are delivered in subsequent consolidation cycles. Administration of fludarabine together with cytarabine increases intracellular concentrations of the latter drug; promising results with this regimen suggests that high doses of cytarabine and a concomitant anthracycline may not be required (19).

The benefit of 3 or more cycles of IDAC/HIDAC consolidation on OS and RFS, especially in patients with inv(16) AML, has been a consistent finding in previously mentioned studies and highlights a different treatment strategy to non-CBF AML subtypes. However, the dose of cytarabine (standard in comparison to intermediate/ high dose) at induction did not impact on OS and RFS in our study. The MRC trial compared high-dose versus intermediate-dose (3 vs $1.5 \mathrm{~g} / \mathrm{m} 2$ ) and reduced number of consolidation cycles (2 vs 3 ) and showed equivalence between the 3 and $1.5 \mathrm{~g} / \mathrm{m}^{2}$ doses (20) although this study used a double-induction strategy which was not utilised in our cohort of patients, thereby limiting its applicability to our cohort.

Consistent with other previous studies $(12,21)$ a recent SWOG study also demonstrated no difference in outcomes for patients treated with standard doses or intermediate doses of cytarabine during induction. The inferior RFS and OS in the CBF AML subgroup of patients who received intermediate dose cytarabine in induction was likely due to the reduced intensity of cytarabine in the subsequent consolidation cycles (22). In a paediatric CBF AML cohort, the benefit of a second reinduction with high dose cytarabine and mitoxantrone only applied to the $t(8 ; 21)$ cohort resulting in higher OS and lower relapse rates (23)

Although we were unable to find a significant benefit of anthracycline dose in our cohort, the importance of anthracycline dose intensification during induction has been demonstrated in favourable and intermediate-risk AML in survival outcomes (24). However, in this study, the CBF AML cohort received a different consolidation regimen in comparison to our cohort, with two cycles of high-dose cytarabine treatment, followed by autologous stem cell transplant with or without gemtuzumab.

Age was a predictor of overall survival. This is consistent with previous studies in AML regardless of cytogenetic type(4). Increasing age is associated with inferior outcomes for complete remission, overall survival, remission duration and relapse-free survival(25). This is thought to be related to the aggressive biology of elderly AML, intolerance to high-intensity 
chemotherapy and underlying comorbidities. In our cohort, there was no correlation with age and number of consolidation cycles received.

For RFS, inv(16) CBF AML subtype was the most significant predictor of inferior outcome. This subtype had a higher median white cell count at diagnosis in comparison to the $t(8 ; 21)$ subgroup, which could reflect a more aggressive, proliferative biology of disease(5). Although we could not demonstrate the independent effect of WCC on relapse and OS outcomes, other groups have shown the importance of WCC in the $t(8 ; 21)$ CBF AML subtype in determining RFS, CR duration and OS (5) but not in inv(16) subtype (26) . KIT and FLT3 mutations are detected in approximately $17 \%$ and $7 \%$ of CBF AML patients respectively(6). The presence of these RTK mutations portended a worse outcome on relapse-free and overall survival. KITD816V mutations have also been associated with increased white cell counts and relapse rates in t(8;21) $\mathrm{AML}(27)$ while in inv(16) AML, KIT exon 8 mutation and high white cell count were shown to impact on RFS and FLT3-TKD mutation on overall survival(3). There was no significant effect of presence of RTK mutations on relapse and OS in our study likely due to low numbers as testing was not offered in our study cohort until 2006.

The ability to monitor molecular MRD with quantitative PCR allows accurate assessment of remission status and prediction of impending morphologic relapse in CBF AML(7-9). In our experience, persistent low level molecular positivity was more prevalent in the t(8;21) cohort, with some cases achieving negativity up to 2 years post-completion of consolidation therapy. The low-level molecular positivity did not translate to increased relapse risk unless there was a persistent rise in qPCR values. We were unable to demonstrate statistical significance of $a \geq 3$ log reduction in transcript level at various time points after induction and consolidation treatments on OS and RFS, likely due to the low patient numbers in the $<3$ log reduction group. MRD-directed treatment intensification has been reported in a Chinese study of $t(8 ; 21)$ patients who were classified as high-risk if they had not achieved a major molecular response $(\mathrm{MMR})$ (defined as $<0.4 \%$ ) after their second cycle of consolidation or molecular relapse with loss of MMR within 6 months of achieving $\operatorname{MMR}(28)$. High-risk patients proceeding to allogeneic stem cell transplantation had lower relapse rates (22\% vs $79 \%)$ and improved disease-free survival ( $62 \%$ vs $20 \%$ ) in comparison to those who received standard chemotherapy. There was no breakdown of the subset of patients in the high-risk group, and as such the benefits on overall survival in patients who had not achieved MMR following second cycle of consolidation, who then proceeded to an allograft in CR1 versus those in molecular relapse with rising qPCR values, is unknown. 
Relapse occurred in 24 out of 68 patients (35\%) with a preponderance in the inv(16) cohort. Approximately two-thirds of our relapsed patients proceeded to salvage treatment with a stem cell transplant (most with an allogeneic donor source) with an OS rate of $54 \%$. There were 2 patients who proceeded to an autograft with ongoing long-term remission supporting the benefit of an autograft in patients who do not have an allogeneic donor option(10). These findings support our current practice of recommending an allogeneic stem cell transplant at time of molecular relapse or achievement of a second remission following frank relapse, but not in first remission(29).

Regular monitoring of PB and BM qPCR values post-completion of treatment is necessary for prediction of subsequent morphologic relapse with early institution of stem cell transplantation during the molecular relapse phase to avoid toxicity associated with additional re-induction chemotherapy treatments. Although limited by data availability in this study, newer markers of prognosis including RTK mutations and molecular MRD have been shown to be relevant in larger data sets and further studies aiming to incorporate them with known traditional risk factors such as age and white cell count to derive a clinically useful predictive prognostic scoring model are warranted.

\section{References}

1. Jaffe E, Harris N, Stein H, Vardiman J. World Health Organization Classification of Tumours: Pathology and Genetics of Tumours of Haematopoietic and Lymphoid Tissues2001.

2. Speck N, Gilliland D. Core-Binding factors in haematopoiesis and leukaemia. Nat Rev Cancer. 2002;2(7):502-13.

3. Paschka P, Du J, Schlenk R, Gaidzik V, Bullinger L, Corbacioglu A, et al. Secondary genetic lesions in acute myeloid leukemia with inv(16)or t(16;16): a study of the German-Austrian AML Study Group (AMLSG). Blood. 2013;121(1):170-7.

4. Appelbaum F, Gundacker H, Head D, Slovak M, CL W, Godwin J, et al. Age and acute myeloid leukemia. Blood. 2006;107(9):3481-5.

5. Nguyen $S$, Leblanc T, Fenaux P, Witz F, Blaise D, Pigneux A, et al. A white cell index as the main prognostic factor in $t(8 ; 21)$ acute myeloid leukaemia (AML): a survey of 161 cases from the French AML Intergroup. Blood. 2002;99(10):3517-23.

6. Boissel N, Leroy H, Brethon B, Philippe N, de Botton S, Auvrignon A, et al. Incidence and prognostic impact of c-Kit, FLT3, and Ras gene mutations in core binding factor acute myeloid leukemia (CBF-AML). Leukemia. 2006;20(6):965-70.

This article is protected by copyright. All rights reserved 
7. Liu Yin J, O'Brien M, Hills R, Daly S, Wheatley K, Burnett A. Minimal residual disease monitoring by quantitativeRT-PCR in core binding factor AML allows risk strftcation and predicts relapse: results of the United Kingdom MRC AML-15 trial. Blood. 2012;120(4):2826-35.

8. Jourdan E, Boissel N, Chevret $S$, Delabesse E, Renneville A, Cornillet $P$, et al. Prospective evaluation of gene mutations and minimal residual disease in patients with core binding factor acute myeloid leukemia. Blood. 2013;121(12):2213-222.

9. Willekens C BO, Renneville A, Cornillet-Lefebvre P, Pautas C, Guieze R, Ifrah N, Dombret H, Jourdan $E$, Preudhomme $C$, Boissel N. Prospective long-term minimal residual disease monitoring using RQ-PCR in RUNX1-RUNX1T1-positive acute myeloid leukemia: results of the French CBF-2006 trial. Haematologica. 2016;101(3):328-35.

10. Fernandez H, Sun Z, Litzow M, SM L, Paietta E, Racevskis J, et al. Autologous transplantation gives encouraging results for young adults with favorable-risk acute myeloid leukemia, but is not improved with gemtuzumab ozogamicin. Blood. 2011;117(20):5306-13.

11. Pautas C, Merabet F, Thomas X, Raffoux E, Gardin C, Corm S, et al. Randomized Study of Intensified Anthracycline Doses for Induction and Recombinant Interleukin-2 for Maintenance in Patients With Acute Myeloid Leukemia Age 50 to 70 Years: Results of the ALFA-9801 Study. Journal of Clinical Oncology. 2010;28(5):808-14.

12. Lowenberg B, Pabst T, Vellenga E, van Putten W, Schouten HC, Graux C, et al. Cytarabine dose for acute myeloid leukemia. N Engl J Med. 2011;364(11):1027-36.

13. Bloomfield CD, Lawrence D, Byrd JC, Carroll A, Pettenati MJ, Tantravahi R, et al. Frequency of prolonged remission duration after high-dose cytarabine intensification in acute myeloid leukemia varies by cytogenetic subtype. Cancer Res. 1998;58(18):4173-9.

14. Miyawaki S, Ohtake S, Fujisawa S, Kiyoi H, Shinagawa K, Usui N, et al. A randomized comparison of 4 courses of standard-dose multiagent chemotherapy versus 3 courses of high-dose cytarabine alone in postremission therapy for acute myeloid leukemia in adults: the JALSG AML201 Study. Blood. 2011;117(8):2366-72.

15. Stone RM. Consolidation Chemotherapy for Adults With AML in First Remission: Is There a Best Choice? Journal of Clinical Oncology. 2013;31(17):2067-9.

16. Cheson BD BJ, Kopecky KJ, Büchner T, Willman CL, Estey EH, Schiffer CA, Doehner H, Tallman MS, Lister TA, Lo-Coco F, Willemze R, Biondi A, Hiddemann W, Larson RA, Löwenberg B, Sanz MA, Head DR, Ohno R, Bloomfield CD. Revised recommendations of the International Working Group for Diagnosis, Standardization of Response Criteria, Treatment Outcomes, and Reporting Standards for Therapeutic Trials in Acute Myeloid Leukemia. Journal of Clinical Oncology. 2003 21(24):4642-9.

This article is protected by copyright. All rights reserved 
17. REQUIREMENTS FOR MEDICAL TESTING OF HUMAN NUCLEIC ACIDS (Second Edition 2013). In: Health, editor. Canberra: National Pathology Accreditation Advisory Council; 2014.

18. REQUIREMENTS FOR THE DEVELOPMENT AND USE OF IN-HOUSE IN VITRO DIAGNOSTIC MEDICAL DEVICES (IVDs) (Third Edition 2014) In: Health, editor. Canberra: National Pathology Accreditation Advisory Council; 2014.

19. Marlton P, Seymour JF, Bradstock K, Lewis ID, Saal R, McMillen L, et al. High Dose Cytarabine (HiDAC) and Fludarabine Without Anthracycline For Patients With Core Binding Factor (CBF) Acute Myeloid Leukemia (AML): The Australasian Leukaemia and Lymphoma Group (ALLG) AMLM13 Study. Blood. 2013;122(21):1444-.

20. Burnett $\mathrm{AK}$, Russell $\mathrm{NH}$, Hills RK, Hunter $\mathrm{AE}$, Kjeldsen L, Yin J, et al. Optimization of Chemotherapy for Younger Patients With Acute Myeloid Leukemia: Results of the Medical Research Council AML15 Trial. Journal of Clinical Oncology. 2013;31(27):3360-8.

21. Willemze R, Suciu S, Meloni G, Labar B, Marie JP, Halkes CJ, et al. High-dose cytarabine in induction treatment improves the outcome of adult patients younger than age 46 years with acute myeloid leukemia: results of the EORTC-GIMEMA AML-12 trial. J Clin Oncol. 2014;32(3):219-28.

22. Garcia-Manero G, Othus M, Pagel JM, Radich JP, Fang M, Rizzieri D, et al.

901 SWOG S1203: A Randomized Phase III Study of Standard Cytarabine Plus Daunorubicin $(7+3)$ Therapy Versus Idarubicin with High Dose Cytarabine $(I A)$ with or without Vorinostat $(I A+V)$ in Younger Patients with Previously Untreated Acute Myeloid Leukemia (AML). American Society of Hematology 58th Annual Meeting and Exposition; San Diego Ca2016.

23. Creutzig U, Zimmermann M, Bourquin JP, Dworzak MN, von Neuhoff C, Sander A, et al. Second induction with high-dose cytarabine and mitoxantrone: different impact on pediatric AML patients with $t(8 ; 21)$ and with inv(16). Blood. 2011;118(20):5409-15.

24. Fernandez HF, Sun Z, Yao X, Litzow MR, Luger SM, Paietta EM, et al. Anthracycline dose intensification in acute myeloid leukemia. N Engl J Med. 2009;361(13):1249-59.

25. Büchner T1 Berdel WE HC, Haferlach T, Schnittger S, Müller-Tidow C, Braess J, Spiekermann K, Kienast J, Staib P, Grüneisen A, Kern W, Reichle A, Maschmeyer G, Aul C, Lengfelder E, Sauerland MC, Heinecke A, Wörmann B, Hiddemann W. Age-Related Risk Profile and Chemotherapy Dose Response in Acute Myeloid Leukemia: A Study by the German Acute Myeloid Leukemia Cooperative Group. Journal of Clinical Oncology. 2009 27(1):61-9.

This article is protected by copyright. All rights reserved 
26. Delaunay J, Vey N, Leblanc T, Fenaux P, Rigal-Huguet F, Witz F, et al. Prognosis of $\operatorname{inv}(16) / t(16 ; 16)$ acute myeloid leukemia (AML): a survey of 110 cases from the French $A M L$ Intergroup. Blood. 2003;102(2):462-9.

27. Cairoli R, Beghini A, Grillo G, Nadali G, Elice F, Ripamonti C, et al. Prognostic impact of c-KIT mutations in core binding factor leukemias: an Italian retrospective study. Blood 2005;107(9):34638.

28. Zhu HH ZX, Qin YZ, Liu DH, Jiang H, Chen H, Jiang Q, Xu LP, Lu J, Han W, Bao L, Wang Y, Chen YH, Wang JZ, Wang FR, Lai YY, Chai JY, Wang LR, Liu YR, Liu KY, Jiang B, Huang XJ. MRD-directed risk stratification treatment may improve outcomes of $t(8 ; 21) A M L$ in the first complete remission: results from the AML05 multicenter trial. Blood. 2013 121(20):4056-62.

29. Dohner H, Estey E, Amadori S, al e. Diagnosis and management of acute myeloid leukaemia in adults: Recommendations from an international expert panel, on behalf of the European LeukaemiaNET. Blood. 2010;115(3):453-74.

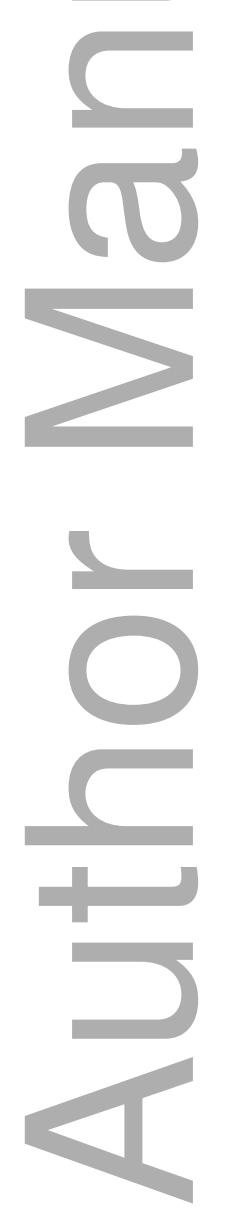


Table 1: Patient demographics, $\mathbf{n}(\%)$ unless otherwise indicated

\begin{tabular}{|c|c|c|c|c|}
\hline$\square$ & Overall (n) & $t(8 ; 21)$ & $\operatorname{inv}(16)$ & p-value \\
\hline Number of Patients & 70 & $40(57)$ & $30(43)$ & \\
\hline Age $\geq 50$ at diagnosis & $27(38)$ & $13(33)$ & $14(47)$ & 0.228 \\
\hline Median Age (Range: 17-73) & 43 & 40 & 46.5 & \\
\hline Male & $39(56)$ & $23(58)$ & $16(53)$ & 0.728 \\
\hline$W C C \geq 40$ at diagnosis & $15(21)$ & $3(8)$ & $12(40)$ & 0.001 \\
\hline Cytogenetics & & & & 0.029 \\
\hline No additional abnormalities & $37(53)$ & $19(47.5)$ & $18(60)$ & \\
\hline Additional abnormality $(<3)$ & $22(31)$ & 15(37.5) & $7(23)$ & \\
\hline$\geq 3$ additional abnormalities (complex) & $11(16)$ & $6(15)$ & $5(17)$ & \\
\hline Trisomy 22 & $2(3)$ & 0 & $2(8)$ & \\
\hline Del Y & $7(10)$ & $7(22)$ & 0 & \\
\hline KIT mutation status & & & & 0.133 \\
\hline Detected & $14(20)$ & $7(32)$ & $7(58)$ & \\
\hline Not Detected & $20(29)$ & $15(68)$ & $5(42)$ & \\
\hline FLT3 mutation status & & & & 1.000 \\
\hline Detected & $2(3)$ & $1(7)$ & $1(8)$ & \\
\hline Not detected & $25(36)$ & $14(93)$ & $11(92)$ & \\
\hline Induction Regimen & & & & 0.953 \\
\hline $7+3$ & $31(44)$ & $22(55)$ & $9(30)$ & \\
\hline HIDAC & $11(16)$ & $4(10)$ & $7(23)$ & \\
\hline Big ICE & $9(13)$ & $4(10)$ & $5(17)$ & \\
\hline FLAG & $9(13)$ & $5(13)$ & $4(13)$ & \\
\hline $\mathrm{IDAC}+3$ & $7(10)$ & $3(8)$ & $4(13)$ & \\
\hline MIDAC & $3(4)$ & $2(5)$ & $1(3)$ & \\
\hline Consolidation 1 & & & & $>0.99$ \\
\hline HIDAC & $38(54)$ & $24(60)$ & $14(47)$ & \\
\hline ICE & $2(3)$ & $1(2.5)$ & 1 (3) & \\
\hline IDAC & $14(20)$ & $7(17.5)$ & $7(23)$ & \\
\hline $5+2+5$ & $5(7)$ & 2 (5) & $3(10)$ & \\
\hline $5+2$ & $3(4)$ & $1(2.5)$ & $2(7)$ & \\
\hline FLAG & $2(3)$ & $1(2.5)$ & $1(3)$ & \\
\hline
\end{tabular}




\begin{tabular}{|c|c|c|c|c|}
\hline MIDAC & $1(1)$ & $1(2.5)$ & 0 & \\
\hline None & $5(7)$ & $3(7.5)$ & $2(7)$ & \\
\hline Consolidation 2 & & & & $>0.99$ \\
\hline HIDAC & $31(44)$ & $20(50)$ & $11(37)$ & \\
\hline $5+2$ & $5(7)$ & $3(7.5)$ & $2(7)$ & \\
\hline IDAC & $12(17)$ & $5(12.5)$ & $7(23)$ & \\
\hline $5+2+5$ & $3(4)$ & $1(2.5)$ & $2(7)$ & \\
\hline MIDAC & $1(1)$ & $1(2.5)$ & 0 & \\
\hline None & $18(26)$ & $10(25)$ & $8(26)$ & \\
\hline Consolidation 3 & & & & 0.97 \\
\hline HIDAC & $19(27)$ & $14(35)$ & $5(17)$ & \\
\hline IDAC & $10(14)$ & $5(12.5)$ & $5(17)$ & \\
\hline FLAG & $1(1)$ & $1(2.5)$ & 0 & \\
\hline None & $40(57)$ & $20(50)$ & $20(67)$ & \\
\hline Consolidation 4 & & & & $>0.99$ \\
\hline HIDAC & $12(17)$ & $10(25)$ & $2(7)$ & \\
\hline IDAC & $1(1)$ & 0 & $1(3)$ & \\
\hline FLAG & $4(6)$ & $1(2.5)$ & $3(10)$ & \\
\hline None & $53(75)$ & $29(72.5)$ & $24(80)$ & \\
\hline Consolidation 5 & & & & $>0.99$ \\
\hline HIDAC & $1(1)$ & $1(2.5)$ & 0 & \\
\hline FLAG & $4(6)$ & $1(2.5)$ & $3(10)$ & \\
\hline None & $65(93)$ & $38(95)$ & $27(90)$ & \\
\hline Consolidation 6 & & & & $>0.99$ \\
\hline FLAG & $1(1)$ & 0 & $1(3)$ & \\
\hline None & $69(99)$ & $40(100)$ & $29(97)$ & \\
\hline Deaths & 16 & $7(18)$ & $9(30)$ & 0.218 \\
\hline Relapses & 24 & $7(18)$ & $17(57)$ & $<0.001$ \\
\hline
\end{tabular}

7+3 - Cytarabine $100 \mathrm{mg} / \mathrm{m}^{2}$ D1-7, Idarubicin $12 \mathrm{mg} / \mathrm{m}^{2}$ D1-3 or Daunorubicin $90 \mathrm{mg} / \mathrm{m}^{2}$ D1-3; HIDAC - Cytarabine $3000 \mathrm{mg} / \mathrm{m}^{2}$ BD D1,3,5,7, Idarubicin $12 \mathrm{mg} / \mathrm{m}^{2}$ D1-3; ICE - Idarubicin 9 $\mathrm{mg} / \mathrm{m}^{2} \mathrm{D1}$-3, Cytarabine $3 \mathrm{~g} / \mathrm{m}^{2}$ BD D1,3,5,7 and Etoposide $75 \mathrm{mg} / \mathrm{m}^{2}$ IV D1-7; FLAG Filgrastim 5micrograms daily from DO until ANC recovery, Fludarabine $30 \mathrm{mg} / \mathrm{m}^{2}$ D $1-5$, Cytarabine 2000 $\mathrm{mg} / \mathrm{m}^{2}$ D1-5; IDAC - Cytarabine $1500-2000 \mathrm{mg} / \mathrm{m}^{2}$ BD on $D 1,3,5$ or Cytarabine $2000 \mathrm{mg} / \mathrm{m}^{2} \mathrm{D1}-4$, both with or without Idarubicin $12 \mathrm{mg} / \mathrm{m}^{2}$ D1-3; MIDAC Mitozantrone $10 \mathrm{mg} / \mathrm{m}^{2}$ D1-3, Cytarabine 500mg/m2 BD D1-4; 5+2+5 - Cytarabine $100 \mathrm{mg} / \mathrm{m}^{2}$ D1-5, Idarubicin $12 \mathrm{mg} / \mathrm{m}^{2} \mathrm{D} 1-2$ + Etoposide $75 \mathrm{mg} / \mathrm{m}^{2} \mathrm{D} 1-5 ; 5+2$ - Cytarabine $100 \mathrm{mg} / \mathrm{m}^{2} \mathrm{D} 1-$ 5, Idarubicin 12mg/m2 D1-2. 
Table 2a - Univariate Analysis of OS $(n=68)$

\begin{tabular}{|l|c|c|c|c|}
\hline \multicolumn{1}{|c|}{ Variable } & Count & HR & $\mathbf{9 5 \%} \mathbf{C l}$ & p-value \\
\hline Gender & & & & \\
\hline Male & $39(55.7)$ & 1 & - & - \\
\hline Female & $31(44.3)$ & 1.10 & $0.41-2.94$ & 0.851 \\
\hline Age (continuous) & & 1.03 & $1.00-1.06$ & 0.032 \\
\hline Age & & & & \\
\hline$<50$ & $43(61.4)$ & 1 & - & - \\
\hline $50+$ & $27(38.6)$ & 2.95 & $1.07-8.14$ & 0.036 \\
\hline WCC & & & & \\
\hline$<40$ & $53(77.9)$ & 1 & - & - \\
\hline $40+$ & $15(22.1)$ & 1.56 & $0.54-4.49$ & 0.411 \\
\hline KIT & & & & \\
\hline Not Detected & $20(58.8)$ & 1 & - & - \\
\hline Detected & $14(41.2)$ & 5.16 & $0.53-50.39$ & 0.158 \\
\hline FLT3 & & & & \\
\hline Not Detected & $25(92.6)$ & 1 & & - \\
\hline Detected & $2(7.4)$ & 5.27 & $0.54-51.21$ & 0.152 \\
\hline Cytogenetics & & & & \\
\hline Inv16 or t(8;21) & $37(52.9)$ & 1 & & - \\
\hline Any additional abnormality $(<3)$ & $22(31.4)$ & 0.29 & $0.06-1.33$ & 0.110 \\
\hline Complex cytogenetics & $11(15.7)$ & 1.39 & $0.43-4.50$ & 0.578 \\
\hline Cytogenetics` & & & & \\
\hline Inv16 or t(8;21) & $37(80.4)$ & 1 & - & - \\
\hline Trisomy 22 or -Y & $9(19.6)$ & - & - & - \\
\hline CBF AML Subtype & & & & \\
\hline $\mathrm{t}(8 ; 21)$ cohort only & $40(57.1)$ & 1 & - & - \\
\hline Inv16 cohort only & $30(42.9)$ & 1.71 & $0.64-4.59$ & 0.287 \\
\hline
\end{tabular}

${ }^{\wedge}$ No deaths in the Trisomy 22 or $-Y$ cohort 
Table $2 b$ - Univariate analysis of RFS $(n=68)$

\begin{tabular}{|l|c|c|c|c|}
\hline \multicolumn{1}{|c|}{ Variable } & Count & HR & $\mathbf{9 5 \% ~ C l}$ & p-value \\
\hline Gender & & & & \\
\hline Male & $39(55.7)$ & 1 & - & - \\
\hline Female & $31(44.3)$ & 1.16 & $0.52-2.59$ & 0.715 \\
\hline Age (continuous) & & 1.02 & $1.02-1.05$ & 0.127 \\
\hline Age & & & & \\
\hline$<50$ & $43(61.4)$ & 1 & - & - \\
\hline $50+$ & $27(38.6)$ & 2.12 & $0.95-4.73$ & 0.067 \\
\hline WCC & & & & \\
\hline$<40$ & $53(77.9)$ & 1 & - & - \\
\hline $40+$ & $15(22.1)$ & 3.77 & $1.64-8.69$ & 0.002 \\
\hline KIT & & & & \\
\hline Not Detected & $20(58.8)$ & 1 & - & - \\
\hline Detected & $14(41.2)$ & 2.16 & $0.48-9.69$ & 0.314 \\
\hline FLT3 & & & & \\
\hline Not Detected & $25(92.6)$ & 1 & - & - \\
\hline Detected & $2(7.4)$ & 1.64 & $0.20-13.61$ & 0.649 \\
\hline Cytogenetics & & & & \\
\hline Inv16 or t(8;21) & $37(52.9)$ & 1 & & - \\
\hline Any additional abnormality $(<3)$ & $22(31.4)$ & 0.52 & $0.19-1.45$ & 0.213 \\
\hline Complex cytogenetics & $11(15.7)$ & 1.06 & $0.35-3.18$ & 0.923 \\
\hline Cytogenetics & & & & \\
\hline Inv16 or t(8;21) & $37(80.4)$ & 1 & - & - \\
\hline Trisomy 22 or -Y & $9(19.6)$ & 0.21 & $0.03-1.62$ & 0.136 \\
\hline CBF AML Subtype & & & & \\
\hline $\mathrm{t}(8 ; 21)$ cohort only & $40(57.1)$ & 1 & & - \\
\hline Inv16 cohort only & $30(42.9)$ & 4.31 & $1.78-10.42$ & 0.001 \\
\hline
\end{tabular}




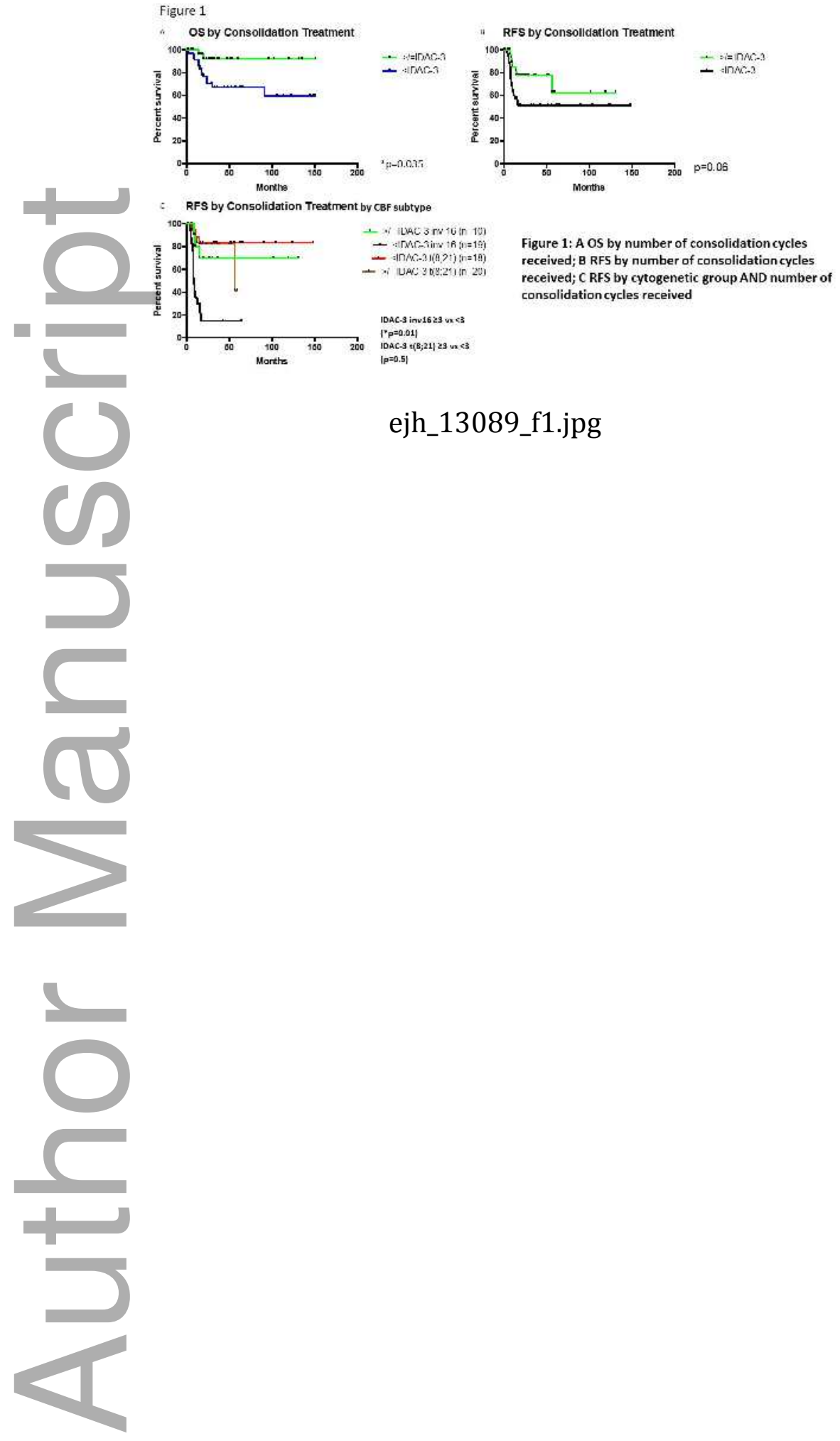

This article is protected by copyright. All rights reserved 


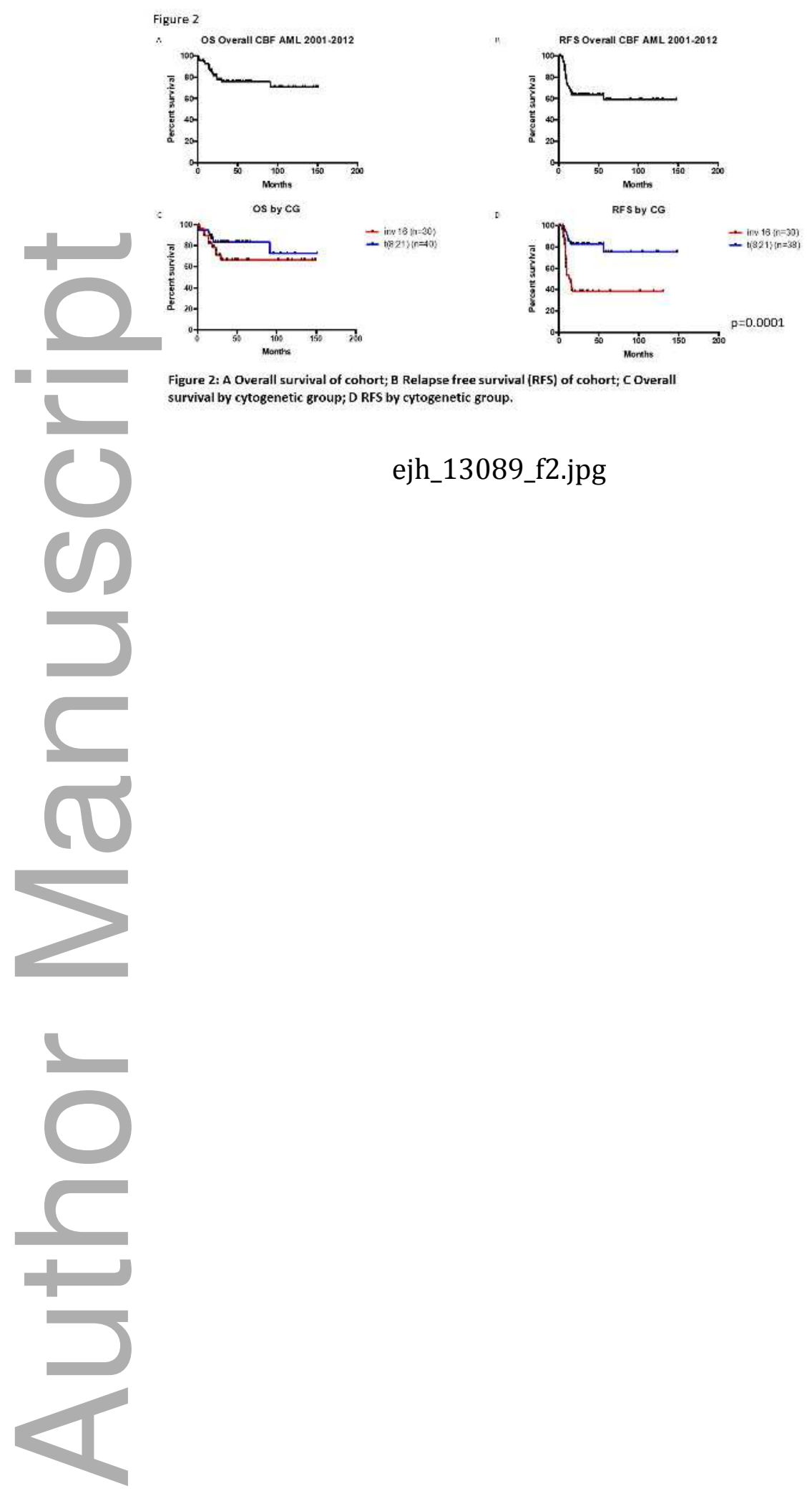

This article is protected by copyright. All rights reserved 


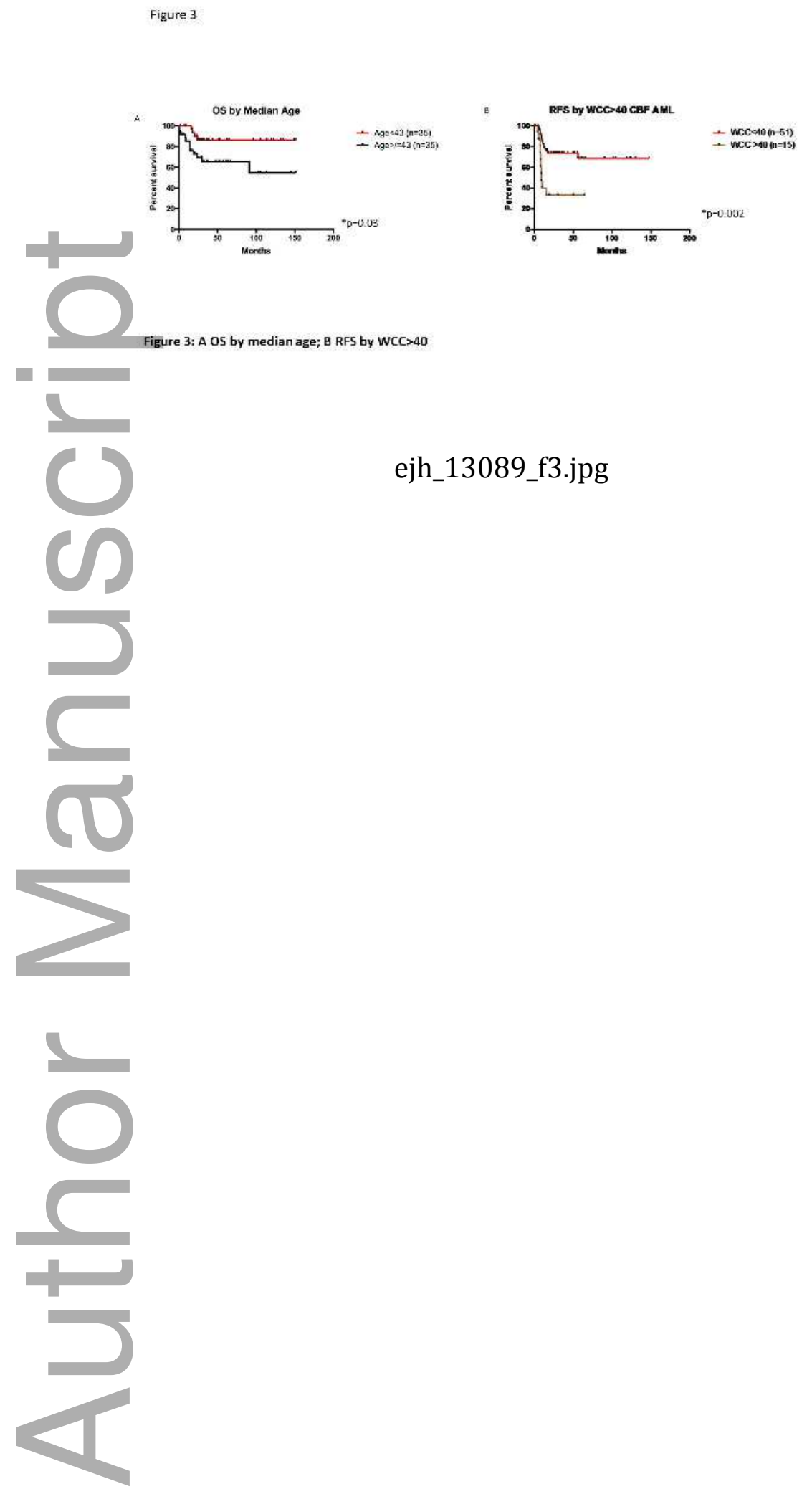

This article is protected by copyright. All rights reserved 


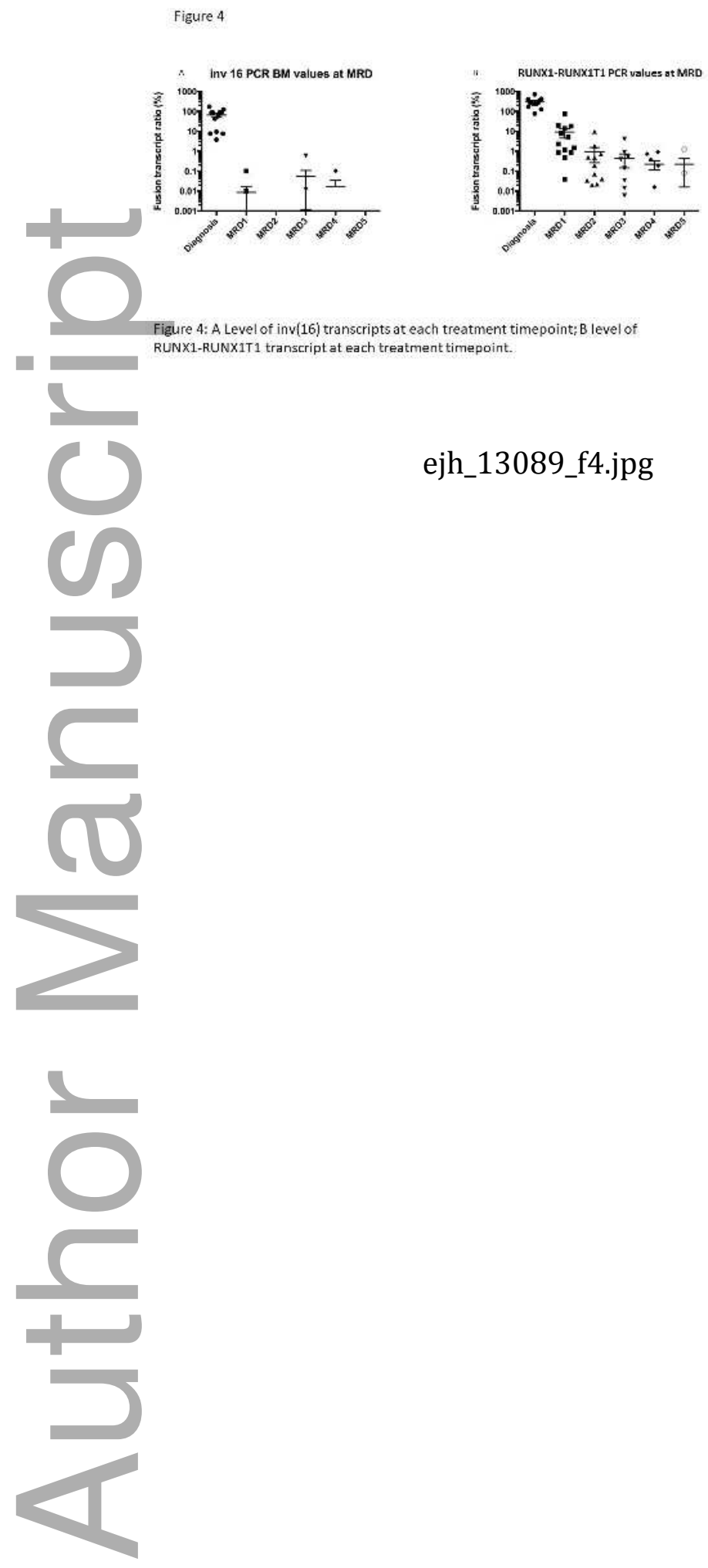

This article is protected by copyright. All rights reserved 


\section{University Library}

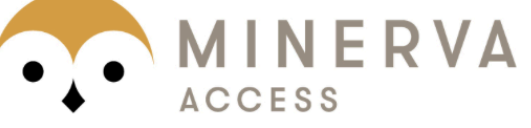

A gateway to Melbourne's research publications

Minerva Access is the Institutional Repository of The University of Melbourne

Author/s:

Prabahran, A;Tacey, M;Fleming, S;Wei, A;Tate, C;Marlton, P;Wight, J;Grigg, A;Tuckfield, A;Szer, J;Ritchie, D;Chee, L

Title:

Prognostic markers in core-binding factor AML and improved survival with multiple consolidation cycles of intermediate-/high-dose cytarabine

Date:

2018-08-01

Citation:

Prabahran, A., Tacey, M., Fleming, S., Wei, A., Tate, C., Marlton, P., Wight, J., Grigg, A., Tuckfield, A., Szer, J., Ritchie, D. \& Chee, L. (2018). Prognostic markers in core-binding factor AML and improved survival with multiple consolidation cycles of intermediate-/highdose cytarabine. EUROPEAN JOURNAL OF HAEMATOLOGY, 101 (2), pp.174-184. https:// doi.org/10.1111/ejh.13089.

Persistent Link:

http://hdl.handle.net/11343/283960 